\title{
sciendo

\section{Particulate Matter Emission Decrease Possibility from Household Sector using Flue Gas Condenser - Fog Unit. Analysis and Interpretation of Results}

\author{
Vivita PRIEDNIECE ${ }^{1 *}$, Elvis KALNINS ${ }^{2}$, Vladimirs KIRSANOVS ${ }^{3}$, Nerijus PEDISIUS $^{4}$, \\ Ivars VEIDENBERGS ${ }^{5}$, Dagnija BLUMBERGA ${ }^{6}$ \\ ${ }^{1-3,5,6}$ Institute of Energy Systems and Environment, Riga Technical University, \\ Azenes iela 12/1, Riga, LV-1048, Latvia \\ ${ }^{4}$ Lithuanian Energy Institute, Breslaujos g. 3, Kaunas, 44403, Lithuania
}

\begin{abstract}
Particulate matter (PM) is a significant pollution problem on the global scale. There are different ways to measure PM from stationary sources. The most used types of PM collection methods include different filters. These include cellulose, glass, mixed and membrane filters. In this study PM samples were measured in the flue gas condenser - fog unit system before and after the unit according to ISO 9096 standard using isokinetic and gravimetric method. PM concentrations after fog unit were measured at different water flows and nozzle types. Impact factors, that effect PM concentrations before and after the fog unit are listed and studied in detail. Achieved results show that the fog unit can be one potential technology for particle matter emission decrease from the household sector.
\end{abstract}

Keywords - Flue gas condenser; flue gas treatment; fog unit household emissions; isokinetic and gravimetric method; particulate matter

\begin{tabular}{|lll}
\hline Nomenclature & & \\
PM & Particulate matter & $\mu \mathrm{g} / \mathrm{m}^{3}$ or $\mathrm{mg} / \mathrm{Nm}^{3}$ \\
$t$ & Temperature & ${ }^{\circ} \mathrm{C}$ \\
$m$ & Mass & $\mathrm{mg}$ or g \\
\hline
\end{tabular}

\section{INTRODUCTION}

Particulate matter (PM) is a term used to describe a mixture of dust particles and small liquid drops. They can be divided by origin into natural and human made particulate matter. Natural PM is caused by volcanic eruptions, vapour, sand and fine particulate transfer with wind, etc. Human made PM comes from different materials, for example, tires, asphalt, flue gas, transport exhaust gases, etc. $\mathrm{PM}$ is one of the main contents of flue gas from solid fuel combustion equipment that promotes increase of emissions in the atmosphere from combustion equipment.

PM can be described by physical and chemical characteristics, such as size and colour, amount, surface area, concentration, density and behaviour. PM can also be viewed as a function of temperature and pressure. It has become a significant pollution problem in many European countries, due to exceeding values of PM concentrations, that are set in EU Directive 2008/50/EC on ambient air quality and cleaner air for Europe [1], [2].

\footnotetext{
* Corresponding author.

E-mail address: vivita.priedniece@rtu.lv
}

C2019 Vivita Priedniece, Elvis Kalnins, Vladimirs Kirsanovs, Nerijus Pedisius, Ivars Veidenbergs, Dagnija Blumberga

This is an open access article licensed under theCreative Commons Attribution License (http://creativecommons.org/ 
The problem of PM pollution is topical throughout the globe. The World Health organization has developed guidelines for created PM, ozone, nitrogen dioxide and sulphur dioxide emissions, that are based on evaluation of data gained through expert-conducted scientific studies and are applicable to any country. Guideline values are set for $\mathrm{PM}_{2.5}$ (fine particulate matter, FPM) and $\mathrm{PM}_{10}$ (coarse particulate matter, CPM). An annual mean for $\mathrm{PM}_{2.5}$ is $10 \mu \mathrm{g} / \mathrm{m}^{3}$, but 24-hour mean should not exceed $25 \mu \mathrm{g} / \mathrm{m}^{3}$. For $\mathrm{PM}_{10}$ annual mean is $20 \mu \mathrm{g} / \mathrm{m}^{3}$, but 24-hour mean is $50 \mu \mathrm{g} / \mathrm{m}^{3}$ [3]. Study done by Steinberga shows that maximum daily concentration of $\mathrm{PM}_{2.5}$ and $\mathrm{PM}_{10}$ at Riga can reach 52.5 $\mu \mathrm{g} / \mathrm{m}^{3}$ at summer months and $83.4 \mu \mathrm{g} / \mathrm{m}^{3}$ at winter months, respectively [4].

A study by Chen et al. shows that in 2015 over $45 \%$ from PM emissions in Europe were created by small capacity combustion units, while industrial wood combustion units can create an amount of PM that is comparable to one measured in densest cities at traffic hours. Studies carried out in China have shown that biomass use in combustion units can make up to 19-37\% of the total PM amount, depending on weather conditions and season, as well the type of biomass used. The parameter of fuel that causes the biggest impact on PM emissions is its moisture content [5], [6]. However, $\mathrm{PM}_{10}$ emission which come from transport sector also must be taken into account to solve pollution problem with solid emissions concentration in the world [7].

There are different ways to measure PM emissions and to determine their concentration that can be found in literature. For example, International Organization for Standardization (ISO) has issued several standards for the determination of stationary source emissions, such as ISO 25597:2013: Test method for determining $\mathrm{PM}_{2.5}$ and $\mathrm{PM}_{10}$ in stack gases using cyclone and sample dilution systems [8] and ISO 9096:2017 for Manual determination of mass concentration of particulate matter [9]. Different PM measurement methods are: integrated light scattering method, electrical low-pressure impactor, the weighing method, gravimetric method, isokinetic method, upwind-downwind method, filter-based methods.

The study of Chen et al. studies the effects of particle size on PM concentration measurements, carried out using the light scattering method and optimization of angle of detection. The light scattering method is a high resolution and accurate, non-invasive method with a wide array of possible applications, especially at low concentrations. Regarding the use of this method in power plants, particle refractive index, density and shape have to be taken into account [10].

The study of Peng et al. studied particle size distribution in different humidity conditions using ELPI (Electrical Low Pressure Impactor). Increased humidity causes increase in total concentration of PM, as shown by results. Condensation and collision-coalescence causes an increase in amount of PM with diameters of $0.1 \mu \mathrm{m}$. Heterogeneous condensation causes a decrease in PM $<0.2 \mu \mathrm{m}$, but increases amount of larger PM, just as collision-coalescence increases PM $>2 \mu \mathrm{m}$. With increased humidity, measures to decrease it have to be considered to obtain accurate PM results. One of the ways to decrease humidity is the use of a Nafion drying tube.

Nafion drying tube is a membrane that selectively removes water from flue gas, without disrupting other components of flue gas. Water moves from high humidity (with high partial pressure) to a low humidity level (low partial pressure). Study shows that the drying tube has a more significant effect on condensation than collision-coalescence [11].

One off-line monitoring method is the weighing method that is used in US and Chinese national standards. This method offers accurate results, but requires long sampling periods that makes it unavailable for automatic monitoring [11].

A study, carried out in the Czech Republic, used an isokinetic gravimetric system to measure $\mathrm{PM}_{10}$ emissions according to ISO 9096 [12]. Another study using the same approaches was made by Khaniabadi et al., where hourly $\mathrm{PM}_{10}$ emission samples were collected in the exhaust pipe from a plant's three stack flow. Equipment used for sampling was Westech M9096 Particulate Sampling Train. They used the upwind-downwind method, that quantifies emissions from different sources as 
pollutant concentration differences between air moving around (upwind-downwind) source site, to measure diffused emissions [13].

There is no PM sampling device with a $100 \%$ efficiency rate. One of the reasons for this is particle bounce, when particle strike and bounce off the collection surface. This might cause losses of already collected particles.

Filter-based PM sampling methods are most used, due to the low cost of filters, easy storage conditions and that they can be used for various analyses of collected PM, they are feasible to different flow volume rates. Filters have different mechanisms for particulate capture from stream. Some of these mechanisms are electrical and gravitational attraction, inertial impaction, direct interception and diffusional deposition. All these mechanisms depend on particle characteristics (composition, size, behaviour), flow rate and filter media type.

Diffusion is the irregular movement of particles, which are suspended in a medium (air). Particle collection rate on a filter by diffusion is dependent on particle concentration gradient, occurring between the filter and air flow through fibres.

Direct interception is similar to mechanical straining. When particle reaches a distance from the filter, equal to or less then its radius, the interception mechanisms occurs and the particle settles on the filter.

Inertial impaction is dependent on mass and velocity of the particle, as it has inertia, when moving in stream. Changes in particle size and filter fibre diameter change the efficiency of inertial impaction collection of PM.

Another PM collection method is electrical force, when particle and filter fibre has opposite electrical charges that attracts particle to filter. However, it has to be noted that, during actual filtration, combined factors of these factors are taking place [14].

TABLE 1. COMPARISON OF PM MEASUREMENT METHODS

\begin{tabular}{|c|c|c|c|c|}
\hline No. & Method & Advantages & Disadvantages & $\begin{array}{l}\text { Suitable for } \\
\text { measurements } \\
\text { in wet flue gas }\end{array}$ \\
\hline 1. & $\begin{array}{l}\text { ISO } \\
25597: 2013\end{array}$ & $\begin{array}{l}\text { Uses cyclone samplers; dilution } \\
\text { sampling technique }\end{array}$ & $\begin{array}{l}\text { Mostly suitable for measurements } \\
\text { of PM concentration }>50 \mathrm{mg} / \mathrm{m}^{3} \text {; } \\
\text { possible PM condensation in } \\
\text { sampling train; limited to } \mathrm{PM} \text { sizes } \\
\text { between } 2.5 \text { and } 10 \mu \mathrm{m} \text {; set } \\
\text { limitations to measuring conditions }\end{array}$ & No \\
\hline 2. & $\begin{array}{l}\text { ISO } \\
9096: 2017\end{array}$ & $\begin{array}{l}\text { Combines gravimetric and } \\
\text { isokinetic methods; applicable to } \\
\text { calibration of automated } \\
\text { monitoring systems }\end{array}$ & $\begin{array}{l}\text { No set weather conditions limits; } \\
\text { PM concentration between } 20 \text { and } \\
1000 \mathrm{mg} / \mathrm{m}^{3} \text {; lower accuracy for } \\
\text { measurements in unstable flue } \\
\text { gases; in stack methods are more } \\
\text { applicable }\end{array}$ & $\begin{array}{l}\text { Depending on } \\
\text { equipment used }\end{array}$ \\
\hline 3. & $\begin{array}{l}\text { Integrated } \\
\text { light } \\
\text { scattering }\end{array}$ & $\begin{array}{l}\text { High resolution and accuracy; } \\
\text { non-invasive; gives PM } \\
\text { concentration and size } \\
\text { measurements; low equipment } \\
\text { maintenance }\end{array}$ & $\begin{array}{l}\text { Possible sensitivity to particles with } \\
\text { size below } 2.5 \mu \mathrm{m} \text {; particle } \\
\text { condensation and evaporation effects } \\
\text { precision; measuring large PM }\end{array}$ & With additions \\
\hline 4. & $\begin{array}{l}\text { Electrical low } \\
\text { pressure } \\
\text { impactor }\end{array}$ & $\begin{array}{l}\text { PM concentrations along with } \\
\text { size distribution; robust and large } \\
\text { size range }\end{array}$ & $\begin{array}{l}\text { Dependent on aerosol density; } \\
\text { possible imprecisions in size } \\
\text { distribution measurements }\end{array}$ & With additions \\
\hline 5. & $\begin{array}{l}\text { Weighing } \\
\text { method }\end{array}$ & High accuracy & $\begin{array}{l}\text { Long sampling periods; manual } \\
\text { monitoring }\end{array}$ & \\
\hline
\end{tabular}




\begin{tabular}{|c|c|c|c|c|}
\hline No. & Method & Advantages & Disadvantages & $\begin{array}{l}\text { Suitable for } \\
\text { measurements } \\
\text { in wet flue gas }\end{array}$ \\
\hline 6. & $\begin{array}{l}\text { Gravimetric } \\
\text { method }\end{array}$ & $\begin{array}{l}\text { Compatible with ISO 9096; uses } \\
\text { filters; offers chemical analysis }\end{array}$ & $\begin{array}{l}\text { Weighing conditions effect } \\
\text { measurements; not suitable for fast } \\
\text { processes }\end{array}$ & With additions \\
\hline 7. & $\begin{array}{l}\text { Isokinetic } \\
\text { method }\end{array}$ & $\begin{array}{l}\text { Compatible with ISO 9096; } \\
\text { specifically designed equipment; } \\
\text { provides representative sample }\end{array}$ & $\begin{array}{l}\text { Complex; time consuming; } \\
\text { specifically used for measurements } \\
\text { in ducts or stacks; uneven } \\
\text { distribution of particles }\end{array}$ & With additions \\
\hline 8. & $\begin{array}{l}\text { Upwind- } \\
\text { downwind } \\
\text { method }\end{array}$ & $\begin{array}{l}\text { Simple concept; PM } \\
\text { measurements for PM sized }<10 \\
\mu \mathrm{m} \text {; suitable for diffused } \\
\text { emissions measurements; can use } \\
\text { filters }\end{array}$ & $\begin{array}{l}\text { Costly and difficult estimations of } \\
\text { concentrations; long measurement } \\
\text { periods, dependent on wind } \\
\text { direction }\end{array}$ & No \\
\hline 9. & $\begin{array}{l}\text { Filter-based } \\
\text { methods }\end{array}$ & $\begin{array}{l}\text { Simple; low cost; easy storage } \\
\text { conditions; variety of analyses; } \\
\text { feasible for different flow volume } \\
\text { rates; combines different PM } \\
\text { capture mechanisms; chemical } \\
\text { analysis }\end{array}$ & $\begin{array}{l}\text { Dependent on particle } \\
\text { characteristics, flow rate and filter } \\
\text { type used }\end{array}$ & $\begin{array}{l}\text { Depending on } \\
\text { filter media } \\
\text { type }\end{array}$ \\
\hline
\end{tabular}

Table 1 summarises only a part of existing PM measurements methods. Mostly in real life applications, combinations of two or more PM measurement methods are combined. For example, ISO 9096:2017 offers a set of requirements that are applicable for the combination of gravimetric, isokinetic and filter-based methods for PM concentration determination. The combination of these methods provides highly accurate PM measurements, but is time consuming and therefore ISO 9096:2017 is applied in this study for measurements of PM concentrations in the fog unit system.

There are different types of filter materials available for PM sampling. These include cellulose, glass, mixed and membrane filters. Cellulose fibre filters are usually called chemical filters, which are designed for liquid-solid separations. Even though designed for a different purpose, these filters have proven to be suitable for application in PM sampling.

Glass fibre filters are made from glass fibre combined together with an organic binder that is afterwards compressed. These filters are suitable for application in high temperatures, up to $540{ }^{\circ} \mathrm{C}$, therefore it is widely used in stack sampling [15]. Quartz fibre filters can be used in applications for up to $1000{ }^{\circ} \mathrm{C}$.

Mixed fibre filters have characteristics of the different fibres that they are made of. Their efficiency and chemical properties depend on contents.

Membrane filters are made of cellulose compounds, such as, cellulose nitrate, PVC, Teflon. These filters are usually used on flat surfaces in controlled atmosphere conditions.

The choice of certain filters depends on many factors, such as: characteristics, PM collection efficiency, possible impurities, conditions at sampling site, chosen method of analysis, flow and light absorption characteristics, just as the purpose for filter application [14].

\section{MethodS}

PM measurements analysed in this study are carried out in the fog unit system. The fog unit system consists of a pellet boiler, ducts, flue gas condenser and has several different measuring points for parameters like water temperature, flue gas temperature, particulate matter amount, flue gas contents and characteristics (velocity, pressure, etc.). The system and its operation are described in detail in the work of Priedniece et al. [16]. Measurements after the fog unit are carried 
out in wet flue gases with different conditions than flue gases after the boiler. Flue gases after the fog unit have high moisture content, low temperature, it can cause moisture condensation in measuring equipment and on filters used during testing. These conditions can lead to inaccuracies in the end results of PM concentrations.

PM measuring method in flue gas after condenser is carried out according to ISO 9096:2017. The used method describes procedure for manual particulate concentration determination in standard conditions from stationary source emissions. Sampling is carried out using inner filtration method in isokinetic conditions. Isokinetic sampling is a type of sampling, where inlet gas velocity in sampling nozzles $\left(v_{\mathrm{n}}\right)$ and direction is the same as for gas in duct $\left(v_{\mathrm{s}}\right)$ at the sampling points.

PM sampling is done at emission source. Before sampling, filters and washing trays are prepared in the laboratory. Filters that apply to terms set in ISO 9096 are used for testing. PM sampling device used in this study is Tecora Isostack G4 (see Fig. 1), which complies with ISO 9096.

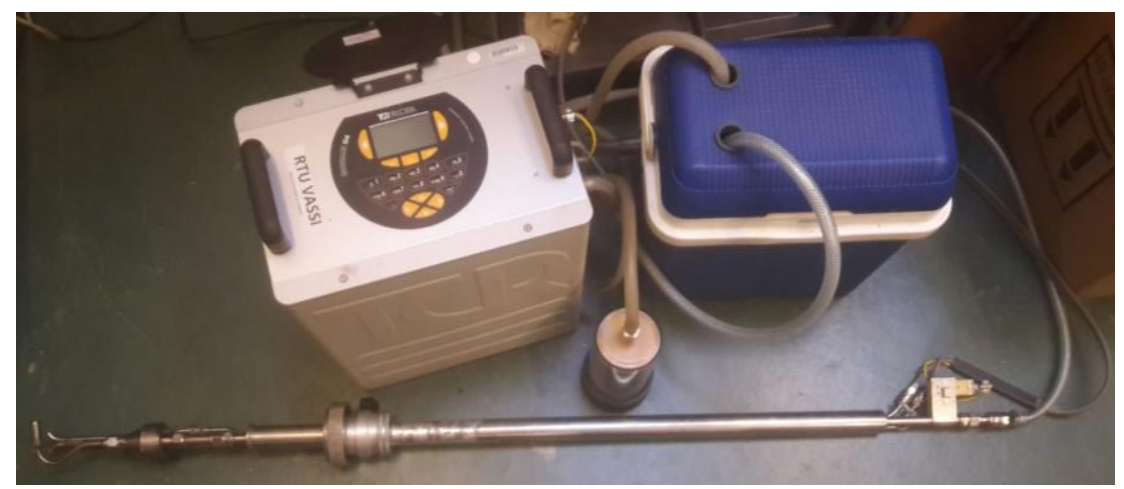

Fig. 1. Tecora Isostack Basic G4 and its main components.

Tecora Isostack G4 is an isokinetic flue gas analyser that consists of suction device with gas measuring system, silica gel (moisture absorbent) trap, Tecora condenser, sampling probe (with temperature sensor and pitot tubes) and connecting pipes, filter holder (filter support, prepared filters, nozzle set), probe nozzle faucet for leak check test, Tecora USB for exporting data.

\subsection{Filter Preparation}

Filters used for PM sampling in this study are round glass fibre filters with a diameter of $47 \mathrm{~mm}$ that conform with requirements of Tecora Isostack G4 and ISO 9096. Filter and washing tray weighing are carried out on analytical weights, with an accuracy of $\pm 0.1 \mathrm{mg}$ when laboratory conditions are less suitable for measurements (drafts or vibrations impact high precision measurements) or $0.01 \mathrm{mg}$, when conditions are suitable for more precise measurements. As weighing time between filter preparation measurements and filter treatment after sampling usually is different by several days, then before every weighing, a set of control procedures are done, to provide representativeness of measurements:

- Inner calibration of analytic weights, using standard weights;

- Weighing of control/reference parts, that is equivalent to one used in measurements (for example, blank filter or tray) and has been kept in the same conditions;

- Registering of environmental conditions (temperature, absolute pressure, relative moisture content) in laboratory. Environmental conditions are registered before every weighing procedure. 
It has to be taken into account, that filter material and particles collected on it can be hygroscopic and volatile. Therefore, weighing has to be done in the first minute after filter removal from desiccator. Strong hygroscopic particles absorb moisture and can change the size of particles, which can in turn impact their sedimentation, collection, removal and deposition on filters and possibly in respiratory system of living organisms. Therefore, it is necessary to follow relative humidity during sampling process and its effect on the results.

\subsection{PM Sampling Process}

During PM sampling, flue gas flow is separated from main gas flow in determined sample collection points with set time of isokinetically controlled flow velocity. Suitable measurement results can be obtained, if:

- The minimum time of measurement is 30 minutes, to collect suitable amount of particulate matter and decrease the possibility of measurement error;

- Gas flow is parallel to probe nozzle axis;

- Gas flow at sampling point has stable and determinable velocity, temperature, pressure and homogeneous gas composition;

- Sampling is carried out, without disrupting gas flow;

- Isokinetic sampling conditions are provided through the whole sampling time, therefore, velocity checks have to be made in sampling plane;

- To provide representative sampling (if PM division in duct is not uniform), samples are collected at previously determined number of points on sampling plane;

- Leaks in the sampling have to be prevented;

- Particulate matter depositions above filter are collected and taken into account in mass concentration calculations;

- After every set of measurements or at least after every day of sampling, a blank sample has to be collected. It allows to evaluate dispersion of results, that is connected with whole procedure, performing it at conditions, when PM concentration is close to zero.

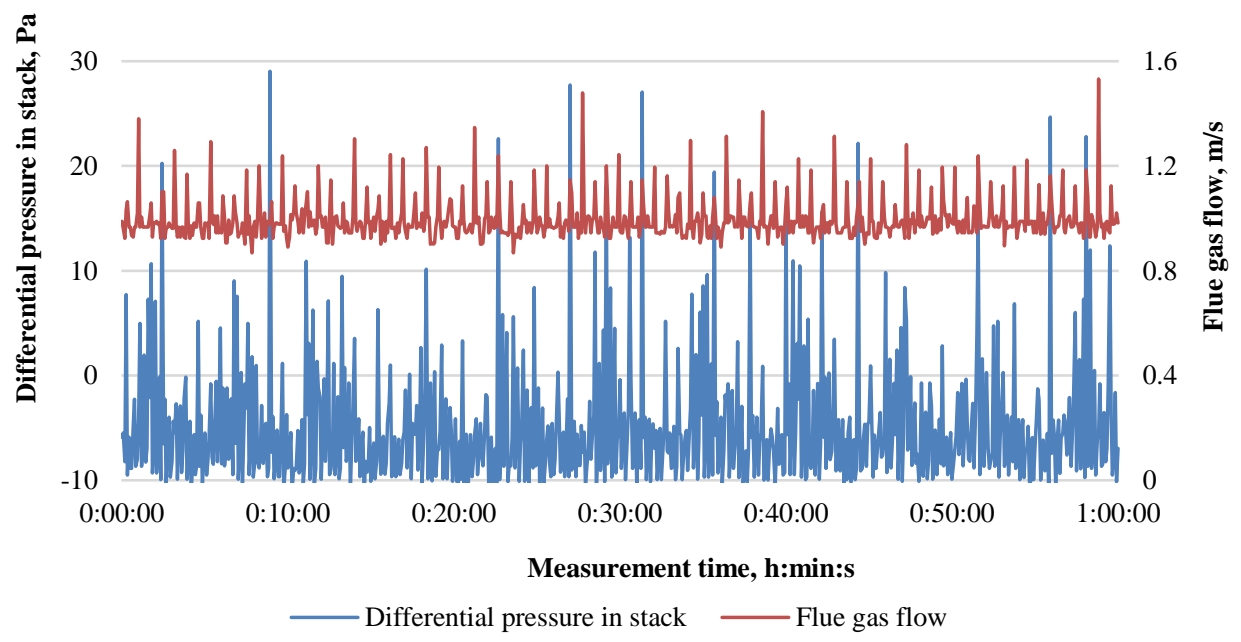

Fig. 2. Changes in differential pressure and flue gas flow over time. 
Unfortunately, it is almost impossible to achieve uniform conditions for measurements of all parameters after the boiler and parameters that leave the biggest impact on PM measurements, such as differential pressure, flue gas temperature and flow fluctuate all the time, as can be seen in Fig. 2.

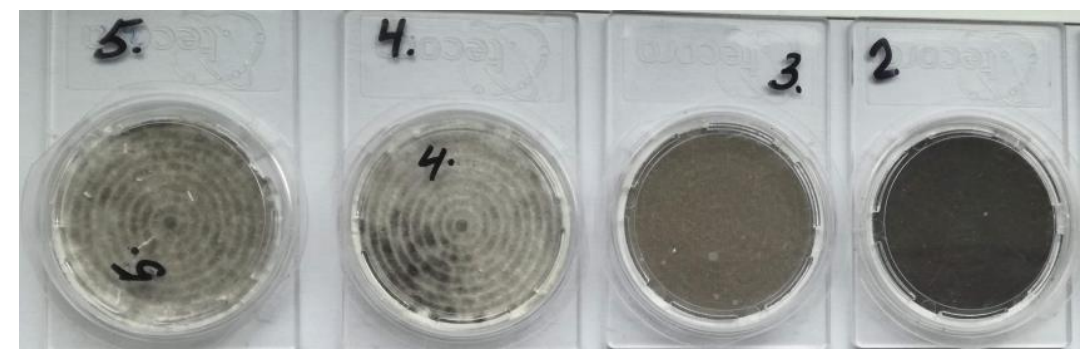

Fig. 3. Filters after different PM sampling test regimes.

As can be seen in Fig. 3, PM concentration on filters differ which is demonstration in their colour. Lighter coloured filters have lower PM concentrations and have been used at bigger water flows, while darker coloured filters have higher PM concentrations with measurement carried out at smaller water flows. In this case filter No. 5 has been used to measure PM after the fog unit at water flow of $200 \mathrm{l} / \mathrm{h}$, filter No. 4 was used for PM measurements after the fog unit at water flow of $150 \mathrm{l} / \mathrm{h}$, filter No. 3 was used after the fog unit at water flow of $50 \mathrm{l} / \mathrm{h}$ and filter No. 2 was used to measure PM concentration before the fog unit (after the boiler) without water spraying. The nozzle used for measurements was MPL0.77 M.

\subsection{Filter Treatment}

After sampling, cartridges (containing used filters) and containers (with washing fluid) are taken back to laboratory for treatment. Treatment includes moving filters and washing fluid to previously prepared trays. Afterwards they are dried in a drying oven. After drying, filters and fluid trays are moved to the desiccator, where they are kept overnight. When filters and trays are ready for weighing, environmental conditions are registered and weights are calibrated. Each mass is registered in a test protocol according to numbering of trays.

Data collected from filter preparation and treatment, testing equipment (Tecora Isostack $G 4$ and flue gas analyser TESTO 350) are used in calculations of PM concentration in standard conditions, according to ISO 9096.

\section{RESUlts}

\subsection{Tests before Fog Unit}

Ten tests were conducted to determine PM measurements after the boiler. The differences in measured PM concentration before fog unit that are affected by various factors are displayed in Fig. 4. Relative humidity and changes in air density create a significant impact on mass measurements over a range of temperature conditions, even when humidity levels are controlled. It has been proven in the work of Rasmussen et al. [17]. The study also shows that increase in relative humidity increases water absorption by PM. The effects of relative humidity on PM measurements can be neglected if PM samples on the filter exceed a mass of $100 \mu \mathrm{g}$. Errors of water absorption are yet to be considered in measurements. 


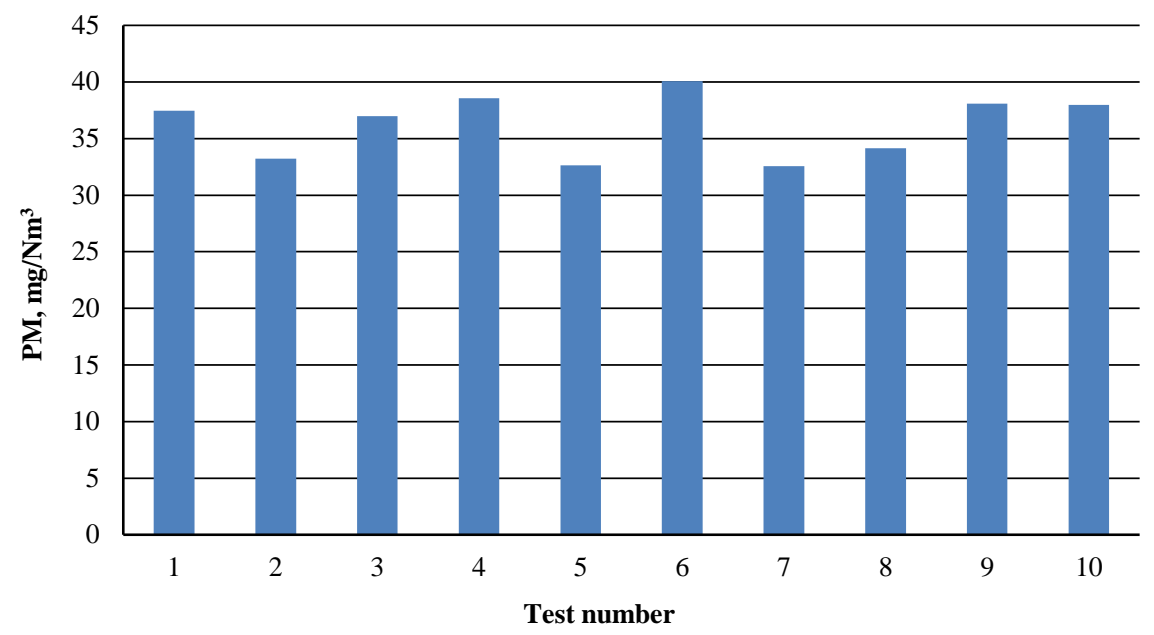

Fig. 4. PM concentrations before fog unit.

As can be seen in the picture, PM concentrations before the fog unit vary depending on measuring conditions and effecting parameters. The highest measured PM concentration achieved during experiments is $40.1 \mathrm{mg} / \mathrm{Nm}^{3}$, while the lowest is $32.6 \mathrm{mg} / \mathrm{Nm}^{3}$, which is achieved in tests No. 5 and No. 7. As mentioned before, PM concentration determination is dependent on filter mass that is affected by environmental conditions and boiler operations. Overall PM amount is affected by temperature and pressure in ducts, where measurements are taken, just as relative humidity of flue gas.

TABLE 2. CONDITIONS FOR PM MEASUREMENTS BEFORE THE FOG UNIT

\begin{tabular}{lllllll}
\hline Test & $\begin{array}{l}\text { Flue gas } \\
\text { temperature, }{ }^{\circ} \mathrm{C}\end{array}$ & $\begin{array}{l}\text { Flue gas } \\
\text { flow, } \mathrm{m} / \mathrm{s}\end{array}$ & Flue gas draft, Pa & $\begin{array}{l}\text { Oxygen } \\
\text { concentration, } \%\end{array}$ & $\begin{array}{l}\text { Boiler } \\
\text { operation } \\
\text { time, } \mathrm{h}\end{array}$ & $\begin{array}{l}\mathrm{PM}, \\
\mathrm{mg} / \mathrm{Nm}^{3}\end{array}$ \\
\hline 1 & 126 & 1.24 & -4.97 & 11.0 & 5.3 & 37.4 \\
2 & 124 & 1.44 & -12.1 & 12.1 & 2.2 & 33.2 \\
3 & 124 & 1.31 & -12.6 & 10.7 & 4.7 & 37.0 \\
4 & 120 & 1.45 & -12.6 & 11.2 & 7.1 & 38.6 \\
5 & 125 & 1.46 & -11.2 & 11.4 & 1.7 & 32.6 \\
6 & 118 & 1.50 & -9.05 & 11.2 & 6.8 & 40.1 \\
7 & 128 & 1.56 & -4.77 & 12.0 & 3.1 & 32.6 \\
8 & 125 & 1.05 & 1.85 & 10.9 & 2.3 & 34.1 \\
9 & 120 & 1.28 & 0.61 & 10.0 & 3.8 & 38.1 \\
10 & 124 & 1.14 & -0.20 & 10.6 & 4.9 & 38.0 \\
\hline
\end{tabular}

Table 2 shows average parameters before the fog unit for every PM test. Even though the boiler was operating in the same regime during all tests, parameters differ in each of them. Flue gas temperature changes from $118{ }^{\circ} \mathrm{C}$ to $126^{\circ} \mathrm{C}$, flue gas flow changes from 1.05 to $1.56 \mathrm{~m} / \mathrm{s}$, flue gas draft is between -12.6 and $0.61 \mathrm{~Pa}$, oxygen concentration in flue gases changes between 10.0 and $12.1 \%$, boiler operation time at the start of PM measuring is from 1.7 to $7.1 \mathrm{~h}$ and $\mathrm{PM}$ 
concentrations differ in a range from 32.6 to $40.1 \mathrm{mg} / \mathrm{Nm}^{3}$. This means that $\mathrm{PM}$ measurements might be affected by changes in the mentioned parameters.

\subsection{Factors Affecting PM Measured Concentration}

Correlation and regression analysis were carried out to see, which of measured parameters in the fog unit system (flue gas temperature, flue gas flow, flue gas draft, oxygen concentration, boiler operation time) affects PM concentration. It was determined that the main parameter that affects PM concentration is boiler operation time. Measurements of PM before fog unit were taken at different operation times of the boiler. A correlation between PM concentration and boiler operation time is significant $\left(R^{2}=0.81\right)$. The PM growth trendline displays how much (in percentage, \%) PM concentration grows when attributed to PM concentration in the $1^{\text {st }}$ hour.

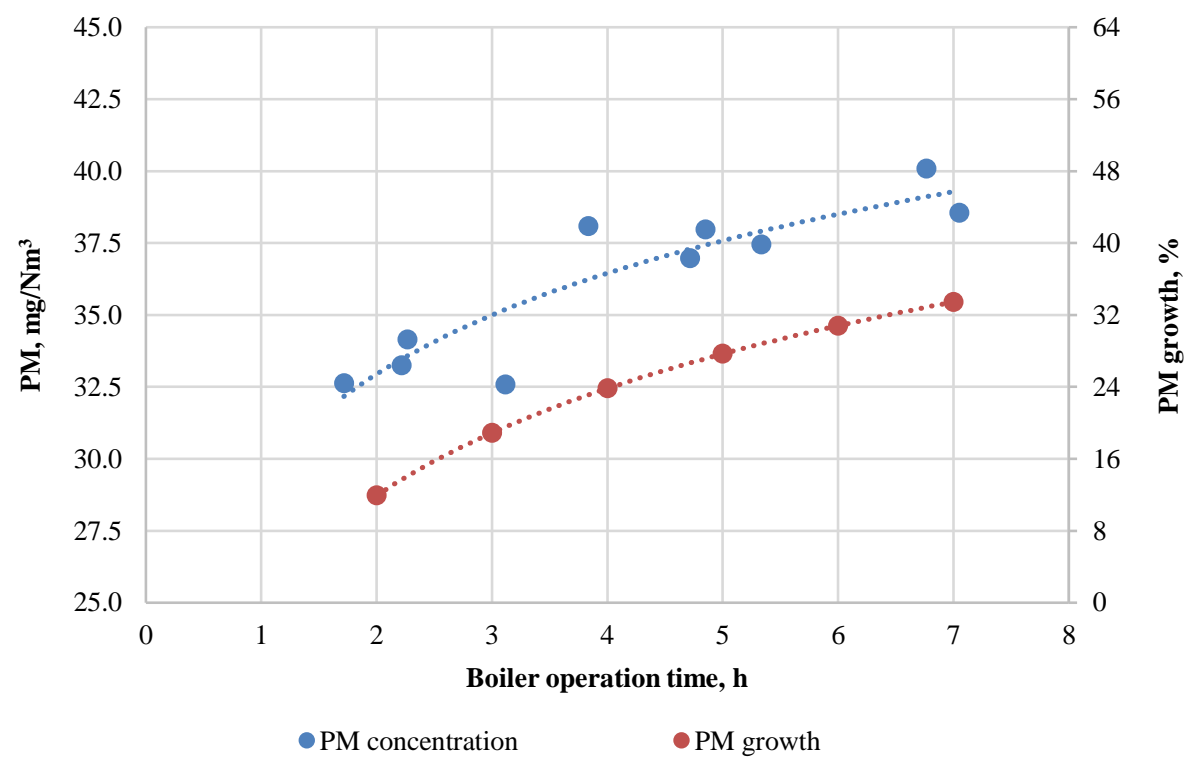

Fig. 5. PM concentration before fog unit depending on boiler operation time.

It should be taken into account that the boiler has an operation stabilisation time of 1 up to 1.5 hours, therefore PM measurements can be performed after stabilisation is reached. Results show that there is an increase in PM concentrations, if measurements are carried out at later boiler operation times.

Data analysis was carried out in Statgraphics. The output shows there is a fitting multiple regression model that describes the relationship between PM concentrations and two independent variables (boiler operation time and oxygen content in flue gas. The Eq. (1) is for the model:

$$
\mathrm{PM}=50.6676+1.14401 \cdot \text { Time }-1.73636 \cdot \text { Oxygen },
$$

where Time is boiler operation time, h; Oxygen is oxygen content in flue gases, $\%$.

The $R^{2}$ value is 0.94 , the $\mathrm{P}$-value is less than 0.05 , describing significant relationship between variables at $95.0 \%$ confidence level. The standard error of residuals is 0.76 . The difference 
between measured and calculated PM concentrations using achieved multiple regression is displayed in Fig. 6.

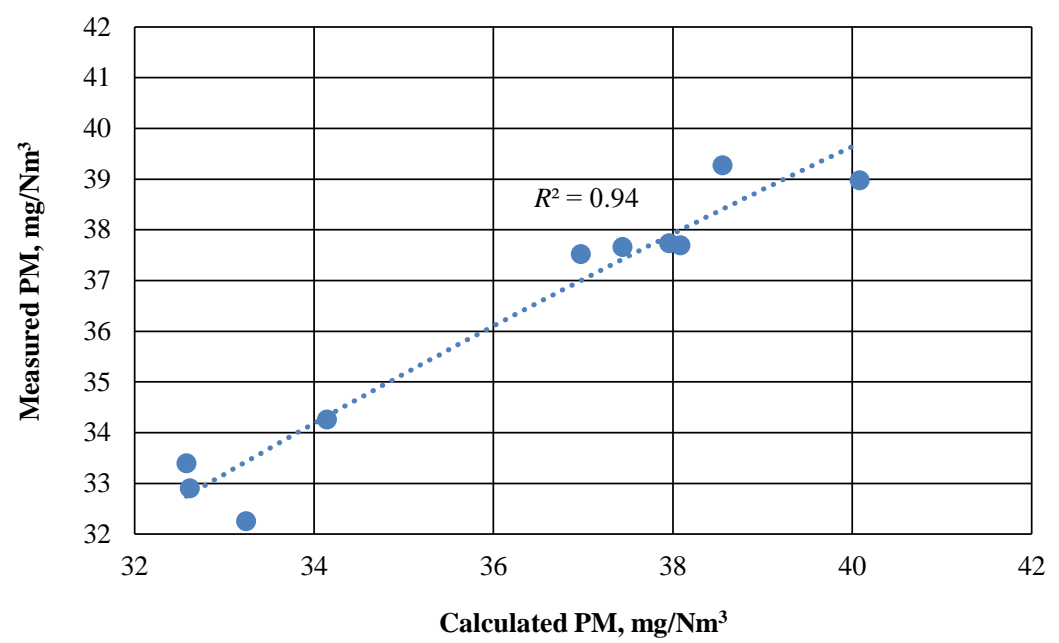

Fig. 6. Comparison of measured and calculated PM concentration values.

TABLE 3. LABORATORY CONDITIONS FOR FILTER WEIGHING

\begin{tabular}{llll}
\hline Parameter & Unit & Min & Max \\
\hline Ambient air temperature & ${ }^{\circ} \mathrm{C}$ & 20.9 & 25.5 \\
Relative humidity & $\%$ & 23.8 & 60.4 \\
Atmospheric pressure & $\mathrm{hPa}$ & 1001.7 & 1027.9 \\
Filter mass & $\mathrm{mg}$ & 145.3 & 146.5 \\
\hline
\end{tabular}

Filter mass changes due to relative humidity are displayed in Fig. 7. The graph presents strong correlation, where increase of relative humidity promotes growth of filter mass, since decrease of relative humidity effect reduction of filter mass. Since relative humidity increase from $23.8 \%$ to $60.4 \%$, the filter mass grows from $145.3 \mathrm{mg}$ to $146.5 \mathrm{mg}$. 


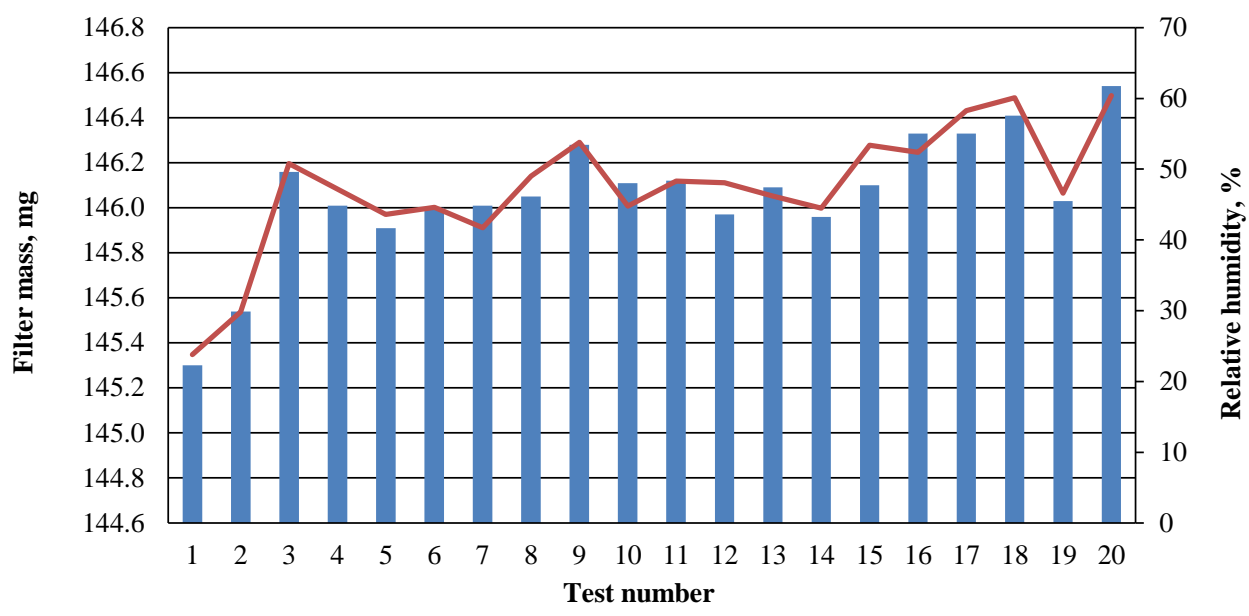

Filter mass $\quad$ Relative humidity

Fig. 7. Filter mass changes due to relative humidity.

Mass of each filter can vary typically in a $\pm 10 \mathrm{mg}$ range. This is the reason why effect of relative humidity must present a relative growth of filter mass. The relationship between relative filter mass changes and relative humidity are displayed in Fig. 8. Relative humidity of $50 \%$ and ambient air temperature of $22{ }^{\circ} \mathrm{C}$ are selected as reference conditions. Even though relative filter mass changes are small $(<1 \%)$, in reality it is from 1 up to $1.5 \mathrm{mg}$ which, compared to PM mass, leaves a significant effect on the end results of PM concentrations.

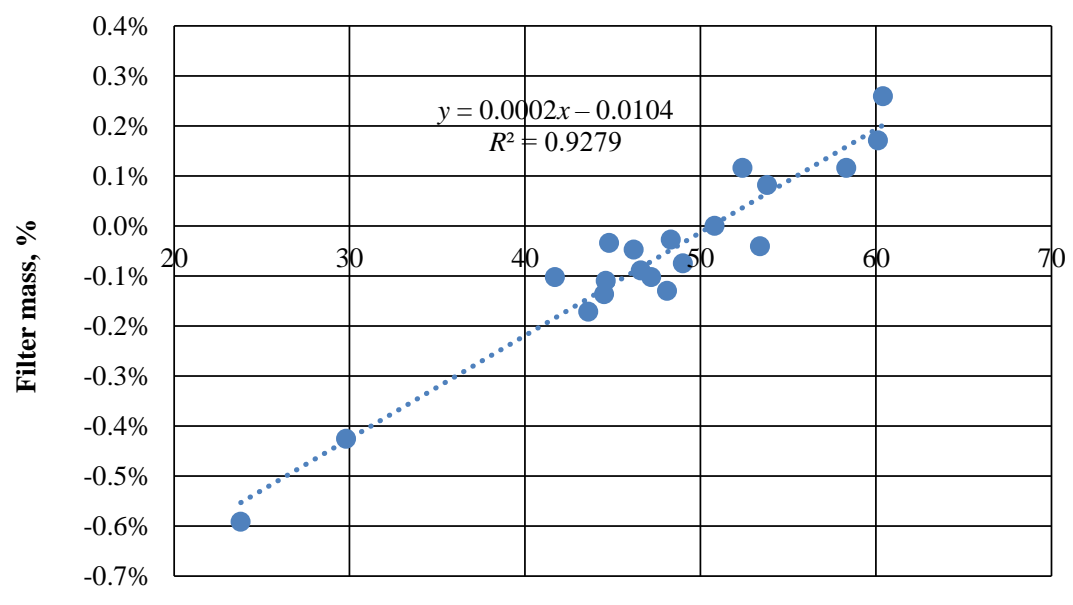

Relative humidity, \%

Fig. 8. Filter mass changes (\%) due to relative humidity changes.

\subsection{PM Concentration after Fog Unit}

During the fog unit experiments, the main parameters that are changed during tests are: sprayed water flow (together with pressure on the nozzle and drop diameter), sprayed water temperature, 
and nozzle type. There are three types of nozzles used during the tests with set operating parameters, see Table 4.

TABLE 4. NOZZLE TYPES AND CHARACTERISTIC PARAMETERS

\begin{tabular}{lllll}
\hline Nozzle type and parameters/Water flow & $501 / \mathrm{h}$ & $150 \mathrm{l} / \mathrm{h}$ & $200 \mathrm{l} / \mathrm{h}$ & $250 \mathrm{l} / \mathrm{h}$ \\
\hline MPL0.77 M; d, microns & 314.9 & 197.3 & 165.7 & - \\
Pressure, bar & 0.4 & 1.9 & 3.4 & - \\
\hline MPL1.12 M; d, microns & 458.7 & 275.0 & 229.9 & 203.6 \\
Pressure, bar & 0.2 & 1.1 & 2.0 & 3.0 \\
\hline MPL1.51 M; d, microns & 788.1 & 395.0 & 320.8 & 273.6 \\
Pressure, bar & 0.05 & 0.5 & 1.0 & 1.7 \\
\hline
\end{tabular}

Particulate matter was measured using all nozzles with set water flows of $50 \mathrm{l} / \mathrm{h}, 150 \mathrm{l} / \mathrm{h}$ and $250 \mathrm{l} / \mathrm{h}$. It was not possible to achieve water flow of $250 \mathrm{l} / \mathrm{h}$ for nozzle MPL0.77 M due to its technical restrictions. There were three water temperature regimes used during testing: $+20{ }^{\circ} \mathrm{C}$, $+30{ }^{\circ} \mathrm{C}$ and $+40{ }^{\circ} \mathrm{C}$, however effects caused by temperature are not considered at the time. Achieved results for every nozzle are displayed in Table 5 and Fig. 9.

TABLE 5. PM CONCENTRATIONS AT DIFFERENT OPERATING REGIMES FOR ALL NOZZLE TyPES

\begin{tabular}{|c|c|c|c|}
\hline Nozzle type & MPL0.77 M & MPL1.12 M & MPL1.51 M \\
\hline Water flow & $\mathrm{PM}, \mathrm{mg} / \mathrm{Nm}^{3}$ & $\mathrm{PM}, \mathrm{mg} / \mathrm{Nm}^{3}$ & $\mathrm{PM}, \mathrm{mg} / \mathrm{Nm}^{3}$ \\
\hline $501 / h$ & $23.4-25.9$ & $19.3-24.1$ & $9.3-22.0$ \\
\hline $150 \mathrm{l} / \mathrm{h}$ & $10.4-15.4$ & $8.2-24.1$ & $9.0-21.2$ \\
\hline $2501 / \mathrm{h}$ & $11.0-22.7^{*}$ & $10.5-11.1$ & 7.9-20.3 \\
\hline
\end{tabular}

*PM concentrations for nozzle MPL0.77 M at water flow of $200 \mathrm{l} / \mathrm{h}$.

At water flow of $50 \mathrm{l} / \mathrm{h}$, PM concentrations change from 9.3 up to $25.9 \mathrm{mg} / \mathrm{Nm}^{3}$, depending on the nozzle. For water flow of $150 \mathrm{l} / \mathrm{h}$, PM concentrations change from 8.2 up to $24.1 \mathrm{mg} / \mathrm{Nm}^{3}$. And at water flow of 200 and $250 \mathrm{l} / \mathrm{h}, \mathrm{PM}$ concentrations change from 7.9 up to $22.7 \mathrm{mg} / \mathrm{Nm}^{3}$. The lowest overall achieved PM concentrations are $9.3 \mathrm{mg} / \mathrm{Nm}^{3}$ for water flow of $50 \mathrm{l} / \mathrm{h}$ using nozzle MPL1.51 M, $8.2 \mathrm{mg} / \mathrm{Nm}^{3}$ at $150 \mathrm{l} / \mathrm{h}$ using nozzle MPL1.12. M, $11.0 \mathrm{mg} / \mathrm{Nm}^{3}$ at $200 \mathrm{l} / \mathrm{h}$ using nozzle MPL0.77 $\mathrm{M}$ and $7.9 \mathrm{mg} / \mathrm{Nm}^{3}$ at $250 \mathrm{l} / \mathrm{h}$ using nozzle MPL1.51 M. These results show that nozzle MPL0.77 M is the least effective of the used nozzles, while nozzles MPL1.12 M and MPL1.51 M show highest efficiencies at different water flows. Further comparison of these nozzles should be carried out in the future.

A more detailed look on PM concentration results is shown in Fig. 9. It shows the range of results for each nozzle type. 


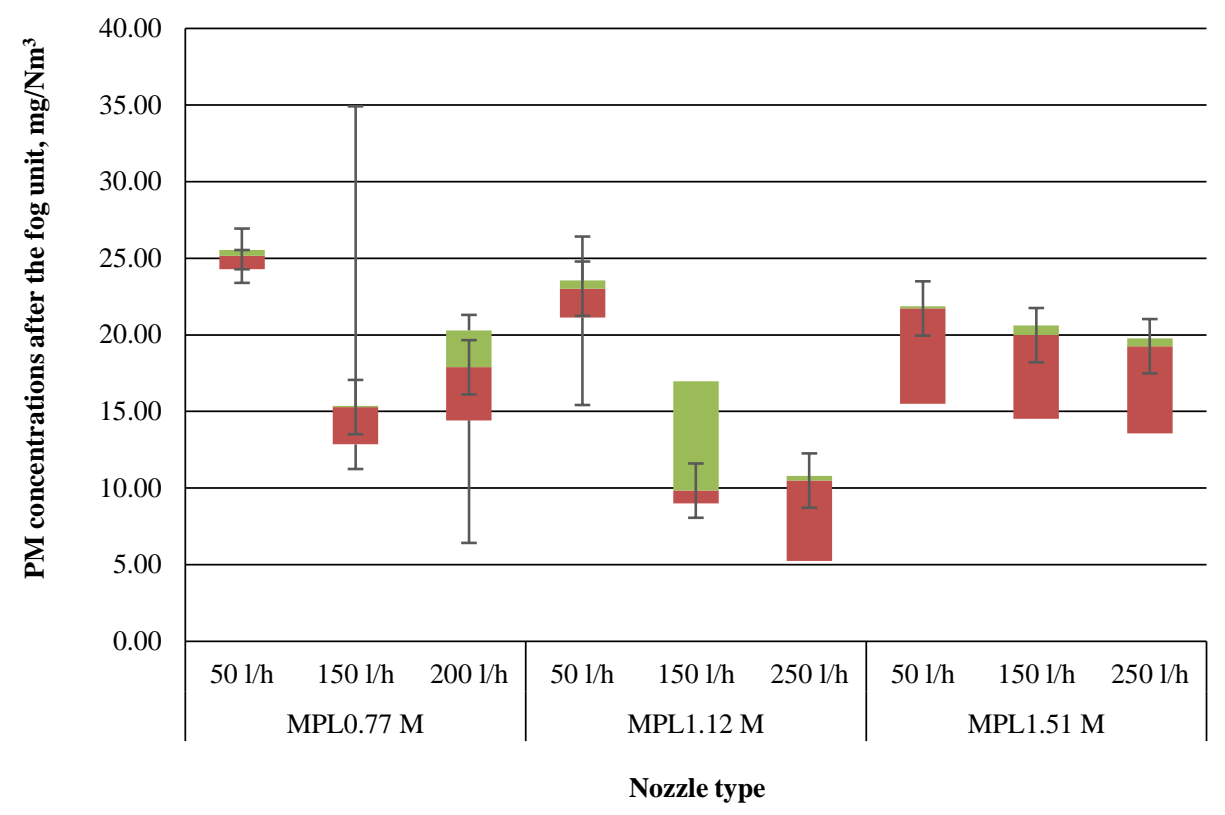

Fig. 9. PM concentrations after the fog unit for used nozzle types.

Fig. 9 displays more detailed PM concentration results for each nozzle at different water flows. As can be seen, the lowest total PM concentrations are achieved with nozzle MPL1.12 M at water flow of $250 \mathrm{l} / \mathrm{h}$ and show the most rapid decrease at different flows, while nozzle MPL1.51 M shows a steady decrease of PM concentrations at different water flows. Nozzle MPL0.77 M proves to be inconsistent in achieved PM concentrations, reaching the lowest values at $150 \mathrm{l} / \mathrm{h}$. The water drop size for nozzle MPL0.77 M at flow $200 \mathrm{l} / \mathrm{h}$ becomes too small and it can be one reason why it not possible to reach lower PM concentration.

Regression analysis was carried out to study PM concentration changes according to nozzle type, water flow and water temperature (at inlet). Analysis was carried out in Statgraphics Centurion 16.1.17 software. The output shows that there are two independent variables that describe PM concentration changes. These parameters are water flow and water temperature. $R^{2}$ value is 0.51 , the $\mathrm{P}$-value is less than 0.05 , which means that there is a significant relationship between variables at $95 \%$ confidence level. The standard error of residuals is 4.53 . The equation for the fitted model is Eq. (2):

$$
\mathrm{PM}_{\mathrm{afg}}=34.6521-0.038531 \cdot W F-0.392484 \cdot t_{\mathrm{w}},
$$

where

$\mathrm{PM}_{\mathrm{afg}} \quad \mathrm{PM}$ concentration after the fog unit, $\mathrm{mg} / \mathrm{Nm}^{3}$;

WF water flow, $1 / \mathrm{h}$;

$t_{\mathrm{w}} \quad$ water temperature at fog unit inlet, ${ }^{\circ} \mathrm{C}$.

The difference between measured and calculated PM concentration values using achieved regression equation is displayed in Fig. 10. 


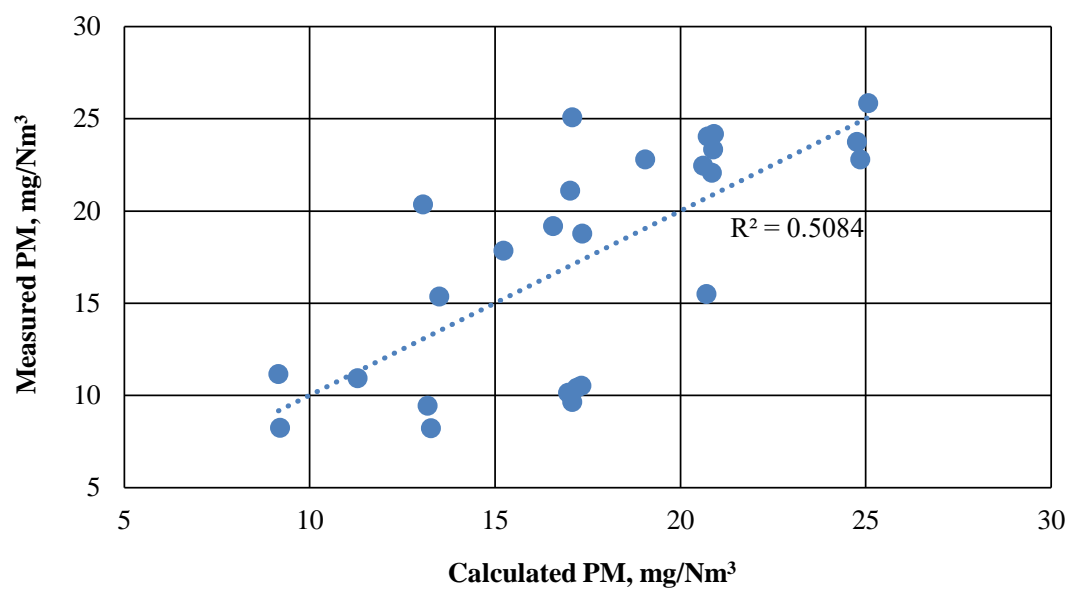

Fig. 10. Comparison of measured and calculated PM concentrations after the fog unit.

As can be seen from the figure above, there are differences between measured and calculated PM values. Results are more similar for smallest PM concentrations of around $10 \mathrm{mg} / \mathrm{Nm}^{3}$. There is close relation between results at high concentrations of around $25 \mathrm{mg} / \mathrm{Nm}^{3}$. Results between these lower and upper values are more dissipated, this might be explained by different measurement conditions during experiments, that might not be as fluctuating in calculations. This leads to necessity for a more detailed analysis of experimental data that affects PM concentrations after fog unit, that should be carried out in future research.

\section{Conclusions}

PM measurements are not uniform in nature and can be affected by various parameters. There are different ways to measure PM concentrations in flue gas, just as there are different materials used for PM capture. This research studies the use of fibre glass filters in PM capturing device in a fog unit system. This means that PM measurements are carried out at dry and wet flue gases. It is concluded, that there are different parameters affecting PM measurement precision. The ones viewed in this research are weather conditions in the laboratory, flue gas characteristics, boiler operation time. It is proved that all of the mentioned parameters leave a significant effect on PM results. When looking at nozzles, results show that nozzle MPL1.12 M and MPL1.51 M are more suitable for use in the fog unit than nozzle MPL0.77 M. The maximal PM concentration reduction $77 \%$ using fog unit technology was achieved using nozzle MPL1.12 M with flow $150 \mathrm{l} / \mathrm{h}$ and MPL1.51 M with flow $250 \mathrm{l} / \mathrm{h}$.

Further studies should be carried out, comparing the two more efficient nozzles to find optimal operation conditions for the fog unit system, considering their efficiency not only at different water flows, but also at different water temperatures. A method to include various effects affecting PM concentration results should be established to reach more precise results in the future. Measured PM concentration will be further analysed, considering all factors that affect PM measurements, which have been defined in section 3.2., like boiler operation time, environmental conditions in laboratory during treatment of filters, etc. 


\section{ACKNOWLEDGEMENT}

The work has been supported by European Regional Development Fund project "Individual Heating with Integrated Fog Unit System (IFUS)" 1.1.1.1/16/A/015.

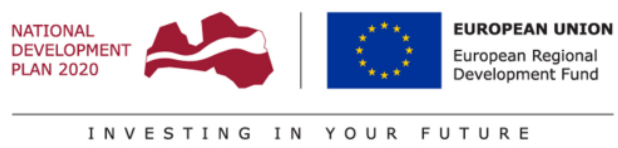

\section{REFERENCES}

[1] Vicente E. D., Alves C. A. An overview of particulate emissions from residential biomass combustion. Atmospheric Research 2018:199:159-185. doi:10.1016/j.atmosres.2017.08.027

[2] Directive 2008/50/EC of the European Parliament and of the Council on ambient air quality and cleaner air for Europe. Official Journal of European Union L152:1-44.

[3] World health organization Media centre. Ambient (outdoor) air quality and health, 2016.

[4] Steinberga I. Variations of particulate matter concentrations and particle-associated substances in Latvia.. Environmental and Climate Technologies 2011:7:113-118. doi:10.2478/v10145-011-0036-9

[5] Chen J., et al. A review of biomass burning: Emissions and impacts on air quality, health and climate in China. Science of The Total Environment 2017:579:1000-1034. doi:10.1016/j.scitotenv.2016.11.025

[6] Clean Heat. Residential wood burning. Environmental impact and sustainable solutions, 2016.

[7] Slisane D., Blumberga D. Assessment of Roadside Particulate Emission Mitigation Possibilities. Environmental and Climate Technologies 2013:12:4-9. doi:10.2478/rtuect-2013-0009

[8] ISO 25597:2013. Stationary source emissions - Test method for determining PM2,5 and PM10 mass in stack gases using cyclone samplers and sample dilution.

[9] ISO 9096:2017. Stationary source emissions - Manual determination of mass concentration of particulate matter.

[10] Chen D., Liu X., Han J., Jiang M., Xu Y., Xu M. Measurements of particulate matter concentration by the light scattering method: Optimization of the detection angle. Fuel Processing Technology 2018:179:124-134. doi:10.1016/j.fuproc.2018.06.016

[11] Peng Y., Sui Z., Zhang Y., Wang T., Norris P., Pan W. P. The effect of moisture on particulate matter measurements in an ultra-low emission power plant. Fuel 2019:238:430-439. doi:10.1016/j.fuel.2018.10.140

[12] Kucbel M., Sýkorová B., Růžičková J. Carbonaceous particles in the air of the Moravian-Silesian Region, Czech Republic. Perspectives in Science 2016:7:333-336. doi:10.1016/j.pisc.2015.11.051

[13] Khaniabadi Y. O., Sicard P., Taiwo A. M., De Marco A., Esmaeili S., Rashidi R. Modeling of particulate matter dispersion from a cement plant: Upwind-downwind case study. Journal of Environmental Chemical Engineering 2018:6(2):3104-3110. doi:10.1016/j.jece.2018.04.022

[14] United States Environmental Protection Agency. Particulate matter sampling. APTI 435 Atmos. Sampl. Course, 2008.

[15] Baitimirova M., Osite A., Katkevich J., Viksna A. Electrochemical Characteristics of Particulate Matter. Environmental and Climate Technologies 2011:7:19-26. doi:10.2478/v10145-011-0023-1

[16] Priedniece V., Kirsanovs V., Dzikevics M., Vigants G., Veidenbergs I., Blumberga D. Laboratory research of the flue gas condenser - fog unit. Energy Procedia 2018:147:482-487. doi:10.1016/j.egypro.2018.07.056

[17] Rasmussen P. E., Gardner H. D., Niu J. Buoyancy-corrected gravimetric analysis of lightly loaded filters. Journal of the Air \& Waste Management Association 2010:60(9):1065-1077. doi:10.3155/1047-3289.60.9.1065

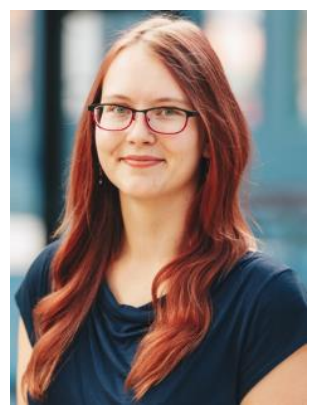

Vivita Priedniece has received B. sc. degree from Riga Technical University (RTU) in 2013. She is on her 2nd year of masters in Environmental Science, RTU.

Author is working at Riga Technical University in the Institute of Energy Systems and Environment as a Scientific Assistant. Current research is related to flue gas cleaning fog unit. Previous publications include:

1. Vivita Priedniece, Toms Prodanuks, Mohamed Marwan Fawzy, Valters Kazulis, Ivars Veidenbergs, Dagnija Blumberga. Biomass co-firing laboratory equipment. In Energy Procedia: https://doi.org/10.1016/j.egypro.2017.04.019;

2. Haralds Vigants, Vivita Priedniece, Ivars Veidenbergs, Dagnija Blumberga. Process optimization for pellets production. In Energy Procedia:

https://doi.org/10.1016/j.egypro.2017.04.021;

3. Jevgenijs Selivanovs, Edgars Vigants, Vivita Priedniece, Ivars Veidenbergs, Dagnija Blumberga. Flue gas treatment multi-criteria analysis. In Energy Procedia: https://doi.org/10.1016/j.egypro.2017.09.056. 

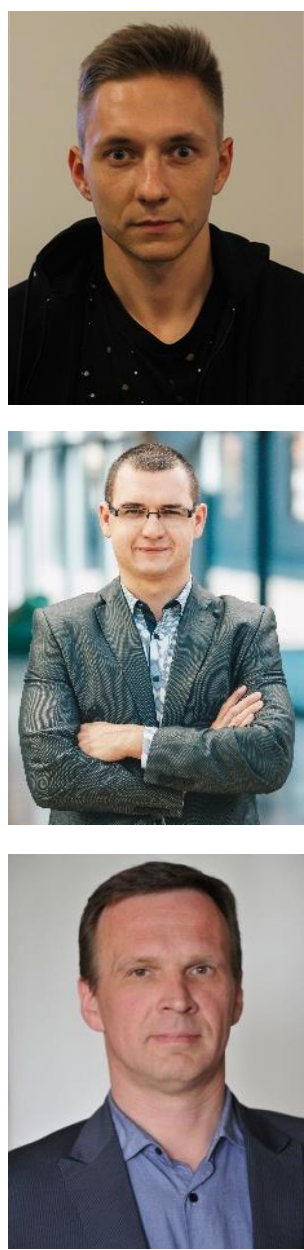

Elvis Kalnins graduated from Koknese high school in 2014 and received a certificate of general secondary education. For a given moment, Elvis works in the Institute of Energy Systems and Environment as a scientific assistant in research and studies at Riga Technical university, Energy and Electrical Engineering faculty, environmental science bachelor program, 3. course. At the moment Elvis is working on project related to flue gas treatment technology "Fog unit", that is innovated here in Riga Technical university. Previous publications as co-author:

- V. Priedniece, E. Kalnins, V. Kirsanovs, D. Blumberga, I. Veidenbergs. Sprayed water flowrate, temperature and drop size effects on small capacity flue gas condenser's performance;

- V.Priedniece, E.Kalnins, V.Kirsanovs, D.Blumberga, I.Veidenbergs. Particulate matter emission decrease possibility from household sector using flue gas condenser.

Vladimirs Kirsanovs has received a Ph. D. degree in Environmental Science in Riga Technical University in 2018 with $\mathrm{Ph}$. D. thesis "Wood chips gasification for syngas production". Vladimirs is working at Riga Technical University in the Institute of Energy Systems and Environment since 2011, currently at position docent and senior researcher. The main research areas are conected with heat and mass exchange processes, biomass combustion and gasification, renewable energy source, energy efficiency, district heating. $\mathrm{He}$ is author of 22 publications, 2 books and 2 patents. Vladimirs has participated in different local and international scientific projects related to energy and environment.

Nerijus Pedisius received the $\mathrm{Ph}$. D. degree in 1997 and since that is working in Lithuanian Energy Institute, Heat-Equipment Research and Testing Laboratory. From 1999 to 2014 he carried out the duties of senior research associate and from 2014 to now he is the head of this laboratory. Field of interest covers:

- Investigations of the properties of solid fuel, thermoconversion of biomass and recovered fuels, efficiency improvement and pollution abatement in small and medium-power plants; - Investigation of fluid flow dynamics and flows mixing in channels and chambers under the influence of flow separation phenomena;

- Provision of accredited and notified services associated with equipment and measurement instrument testing, type approval and conformity assessment;

- Maintenance and improvement of five national standards for liquid and air (gas) flow rate, volume speed and pressure.

$\mathrm{He}$ is the member of the council of National Accreditation Bureau and chairman of the technical committee TC 34 Metrology at Lithuanian Standards Board.

For the past 5 years, he has been a co-author of 10 articles in the Clarivate Analytics WoS database.

ORCID ID: https://orcid.org/0000-0002-5871-1660

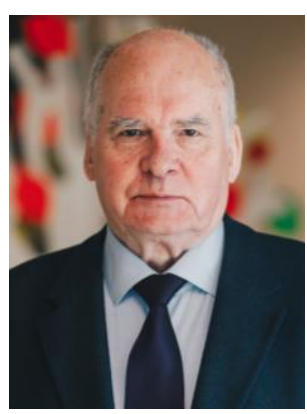

Ivars Veidenbergs, Dr. habil. sc. ing., professor has been a part of academic staff of the Institute of Energy Systems and Environment, Faculty of Energy and Electrotechnics, Riga Technical University. He has thermal engineer diploma (1960) in speciality "Thermal equipment of thermal power stations" and two steps doctoral degree diploma. Ph. D. thesis "Dynamic Temperature Regimes of Thermoelectric Cooling Devices" was defended in Riga Polytechnic Institute (1975). Doctor Habilitus Thesis "Engineering Methods for Calculating Hear and Mass Transfer in the devices of Power Units" was defended in Faculty of Energy and Electronics, Riga Technical University (1992). The main research area is energy and environment. He is the author of more than 180 publications and 5 books. 


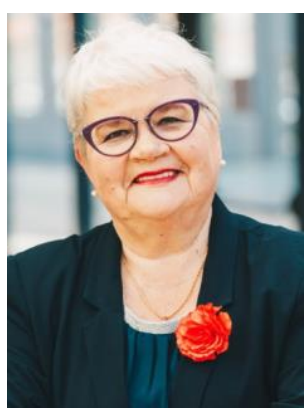

Dagnija Blumberga, Dr. habil. sc. ing., professor, director of the Institute of Energy Systems and Environment, Riga Technical University. Her two-step doctoral degree "Condensing Unit" was defended in Lithuanian Energy Institute, Kaunas (1988). Doctor Habilitus Thesis "Analysis of Energy Efficiency from Environmental, Economical and Management Aspects" was prepared in Royal Institute of Technology (KTH) Stockholm (1995) and was defended in Riga Technical University (1996).

Dagnija Blumberga has been part of academic staff of Riga Technical University since 1976 and director of Institute of Environmental Protection and Energy Systems since 1999.

The main research area is renewable energy resources. She has participated in different local and international projects related to energy and environment as well as an author of more than 200 publications and 14 books.

ORCID ID: https://orcid.org/0000-0002-9712-0804 